\title{
Analysis on the Regulation and Countermeasures of Transportation Structure Adjustment in China
}

\author{
Jianbao Zhang ${ }^{\text {a }}$, Linan $\mathrm{Du}^{\mathrm{b}}$ \\ China Waterborne Transport Research Institute, Beijing 100088, China \\ azhangjianbao@wti.ac.cn, bdulinan@wti.ac.cn
}

\begin{abstract}
The adjustment of transport structure is an important strategic plan for the new era to win the blue-sky defense and to build a beautiful China. Taking the United States as an example, this paper illustrates the objective regularity of the adjustment of transport structure, makes a thorough analysis of the current situation and existing problems of the adjustment of transport structure in China, and puts forward some suggestions for promoting the adjustment of transport structure.
\end{abstract}

Keywords: Transportation Structure Adjustment; Battle of blue sky; Integrated transportation system; Multimodal transport.

\section{Introduction}

The transportation structure adjustment is a major decision deployment of the CPC Central Committee that takes Comrade Xi Jinping as the core, and a strong support for vigorously implementing air pollution prevention and control, resolutely winning the Blue-Sky Protection Campaign and building a beautiful China. Speeding up the adjustment of transportation structure, taking strong and effective control measures, strengthening the demand management of freight logistics market, reducing or even avoiding unreasonable road transport as soon as possible to transfer more medium and long distance bulk cargo transportation from road transportation to railway and waterway transportation orderly, giving full play to the combined advantage and overall efficiency of various modes of transportation, and focusing on building the integrated transportation service structure of "if railway transportation is suitable then can be chosen, if waterway transportation is suitable then can be chosen, and if road transportation is suitable then can be chosen", which will be conducive to improving the overall efficiency of the operation of the integrated transportation system, promoting the upgrading of logistics quality and efficiency, optimizing the allocation of resources, improving the production efficiency of the whole factor, providing the core impetus for the construction of the traffic power, and contributing to winning the Blue Sky Protection Campaign and impelling ecological civilization construction.

In addition, in the new era, the transition from high-speed growth to high-quality development, and from the total expansion to structural optimization of China's economy and society means that the realization of high-quality economic development requires the optimization and upgrading of economic structure, which will result in accelerated upgrading of transportation demand. The profound revolution of residents' travel model and the way of cargo movement, the increasing demand of people in the environment, safety and other aspects, and the growth of the demand of small batches, multi-frequency and customization in logistics, freightage and other aspects put forward new requirements for transportation costs, quality and efficiency. Speeding up the adjustment of transportation structure is an inevitable choice to adapt to the industrial structure upgrading, the productivity layout adjustment and the needs of good living for people, and to realize the transition from the low-end supply and demand balance to the high-end supply and demand balance.

\section{The Evolution Trend of Transportation Structure}

\subsection{Case: The Evolution Process of US Transportation Structure}

With the expansion of US economy and the advancement of the industrialization process, US cargo volume has also achieved a rapid growth. In terms of freight structure: 
Railway: Under the influence of American railway development, the railway freight market share has experienced the process of "high-decline-rise". According to relevant information, when experiencing the early flourish by government funding, railway undertook about $75 \%$ of the freight turnover in 1930s; since then, the United States government began to impose intervention on railway to adopt a series of control measure to break the monopoly of railway transportation and promote the development of roads and aviation transportation, which caused a sharp decline in the railway market, and the railway freight market share reduced to $22.33 \%$ by 1980 ; with the increasing growth of public demand for environmental protection, the quality of transportation service and efficiency, the famous Staggs Act was passed in 1980, and many measures of control on railway were cancelled, which strongly contributed to the railway recovery, and the improvement of transport efficiency and railway passenger volume, therefore, the United States railway based on freight transportation was gradually recovered, and achieved a 33.15\% freight turnover in 2015.

Highway: Highway accounted for about 4\% freight market shares in 1930; however, since 1956, the United States Federal Government has introduced a series of bills to form a sound highway investment and financing system and a legislative system, especially the Federal Funding Highway Act in 1965 and Road Tax Act, which solved the funding shortage of interstate highway construction and ushered in the time of large-scale interstate highway construction. The market shares of highway quickly increased to $30.35 \%$ in 1980 , more than $45 \%$ in 2008 , though there was a little decrease in 2012, still over $38 \%$.

As a whole, the market shares of inland water transportation and pipeline transportation show a downward trend, but in recent years, there is a rising and relatively stable state, they accounted for $9.32 \%$ and $18.38 \%$ respectively in 2015 ; the market shares of air freight is the smallest, only $0.24 \%$.

From the graph below, we can find that the railway resumed growth, the highway still be dominant, the proportion of inland waterway transportation was declined, but ultimately maintained a relatively stable level since 1980s. In 2015, the highway transportation accounted for about $38 \%$, the railway transportation accounted for $33 \%$, the proportion of inland waterway transportation was declined, but maintained at about $10 \%$ in the United States freight structure.

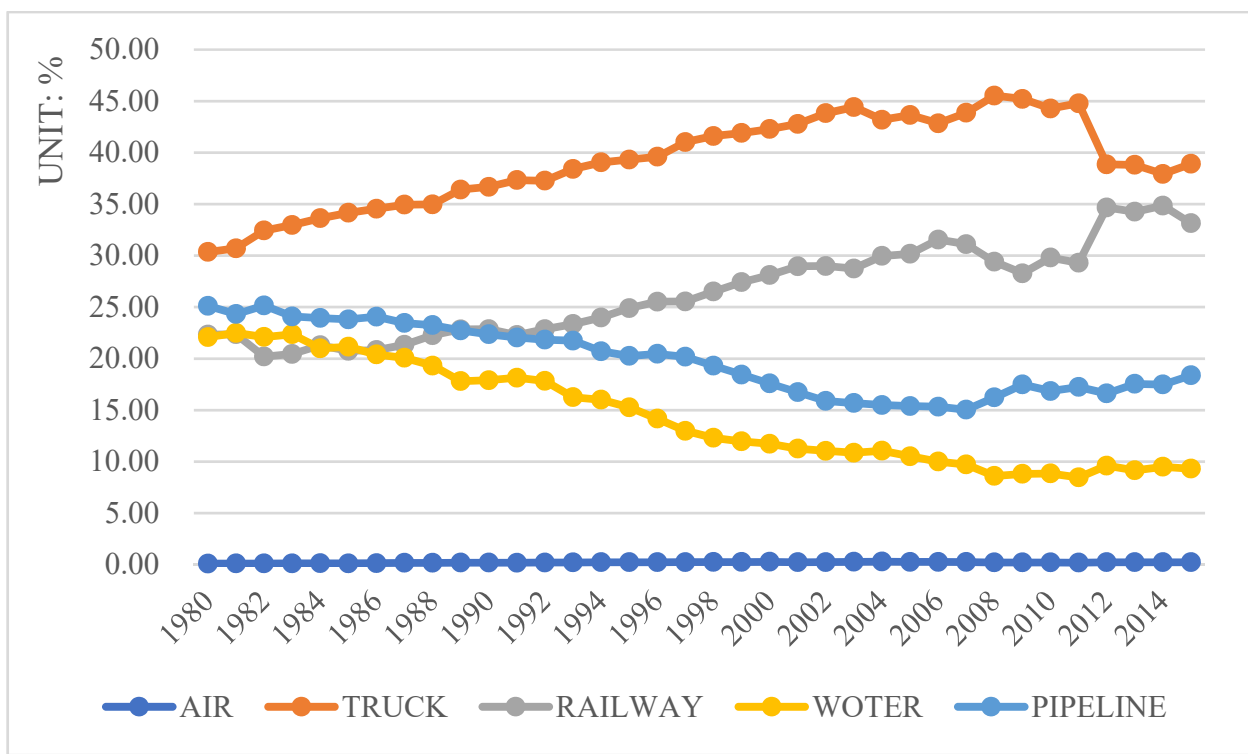

Fig 1. the proportion of rotation volume of freight transport by various transportation ways in USA

\subsection{The Regularity of Transportation Structure Evaluation}

The growth of rotation volume of freight transport of railway and water transport (bulk goods transportation) in the initial and accelerated stages of heavy and chemical industrialization is rapid, but when entering the mature stage, the growth of rotation volume of freight transport of largecapacity transport mode is slow down quickly, or even negative; the relative status of highway transportation (small- capacity transportation and flexibility) is obviously improved. 
As the society has a higher demand on environmental protection, efficiency and cost, the advantages of railway and water transportation such as large capacity, low energy consumption and low cost are gradually favored by the market again, in addition to technological innovation, both of them continually increase their own efficiency and reduce costs, the proportion of which will also rise again, and maintain a relatively reasonable proportion. (When considering ocean shipping, water transportation will be more important in the whole transportation system).

Therefore, quickening the advancement of transportation structure adjustment, promoting the transfer from highway to railway and water transportation of bulk cargo and long-distance unreasonable transportation, which conforms to the general law of transportation structure evolution, and is also an objective requirement to adapt to China's economic and social development.

\section{The Evaluation Process and Problem Analysis of China's Transportation Structure}

\subsection{The Evaluation Process of China's Transportation Structure}

\subsubsection{Volume of Freight Traffic Structure}

The volume of freight traffic of highway has always dominated the total volume of the whole society, and we can find that the proportion of highway volume has climbed from less than $50 \%$ to nearly $80 \%$ for taking private lorry transportation into statistics since 1984 . At the same time, the proportion of railway transportation in China's freight market directly reduces to $17.53 \%$ from about $40 \%$, maintains a declining status, and only is $7.6 \%$ in 2016 . The proportion of waterway transportation volume peaked in the early 1960 s, nearly $20 \%$, it was $8.59 \%$ (regardless of statistical factors, waterway transportation volume should continually grow) because of changing the statistical caliber in 1985, surpassed the railway transportation volume in 2010, and reached $14.55 \%$ in 2016 . The proportions of civil aviation and pipeline transportation volume are small, $0.02 \%$ and $1.67 \%$, respectively.

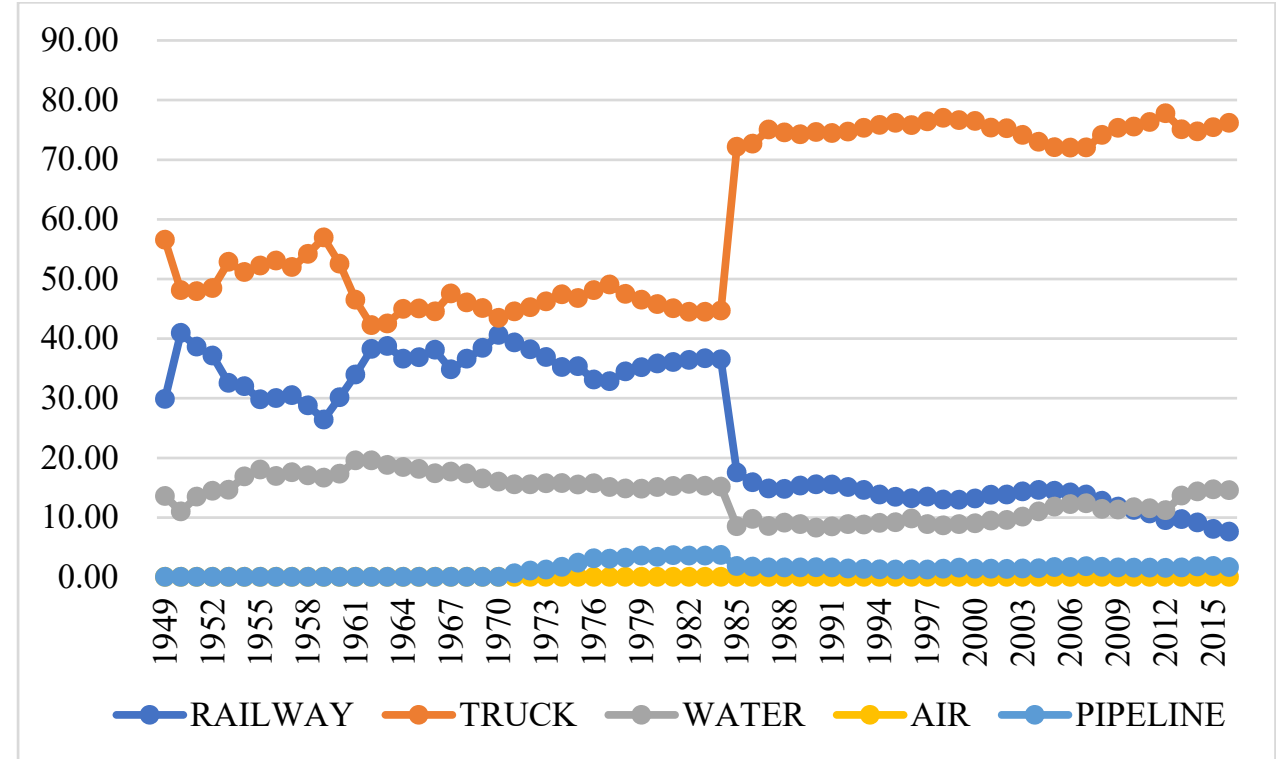

Fig 2. the proportion change of rotation volume of freight transport by various transportation ways in China from 1949 to 2016

\subsubsection{Rotation Volume of Freight Transport Structure}

In the early days of the founding, the railway transportation occupied an absolute dominant position in China's freight market, with a maximum proportion of $86.17 \%$, while the highway transportation only accounted for $2.6 \%$. With the continuous development of China's social economy, the structure of cargo transportation is also gradually changing. Since early 1970s, the rotation volume of freight transport of highway declined greatly, water transportation and highway transportation 
achieved a rapid growth, the rotation volume of freight transport of waterway surpasses railway in 1988, highway transportation exceeds railway in 2008, and became the second largest transportation mode of rotation volume of freight transport. By 2016, the rotation volume of freight transport of railway accounted for $12.75 \%$ of the country's total rotation volume, water transportation and highway transportation accounted for $52.16 \%$ and $32.73 \%$ respectively. The proportions of rotation volume of civil aviation and pipeline transportation are small, but maintain a steady rise to be $0.12 \%$ and $2.25 \%$ respectively in 2016 .

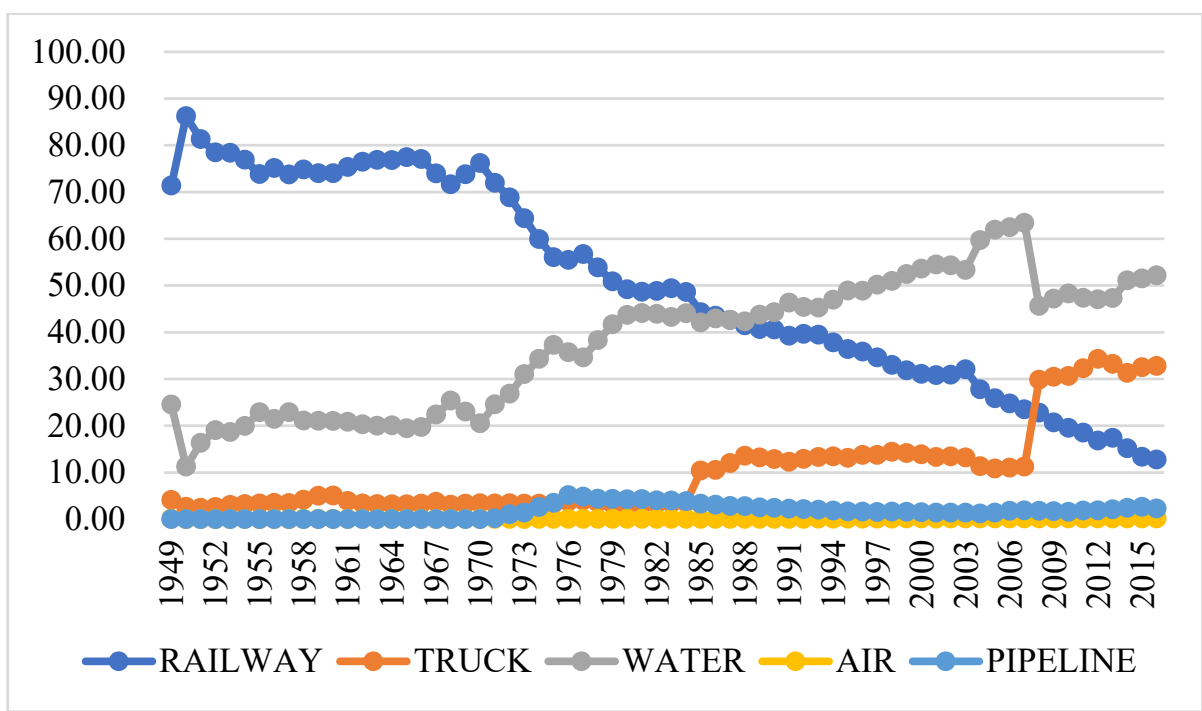

Fig 3. the proportion of rotation volume of freight transport by various transportation ways in China from 1949 to 2016

\subsection{The Reason Analysis of Unreasonable Freight Structure of China}

On the whole, the unbalanced situation of various transportation modes in China is serious, the transportation structure contradiction is becoming more and more prominent, the freight structure of China is not in line with the environment-friendly and resource-saving development needs, and the comparative advantages of various transportation modes have not been fully utilized, the prominent manifestation of which is: the proportion of highway freight transport is too high, the advantages of low emission and high efficiency of railway and waterway transportation have not been effectively released, and transportation structure adjustment is severe.

China's highway transportation bears an excess of medium and long distance cargo transportation, and its freight volume and cargo turnover volume maintain a high proportion for a long time, which result in the comparative advantages of intensive safety, low energy consumption, and low emissions of railway and waterway transportation cannot be fully utilized; according to relevant research data, the volume of over 800 kilometers long-distance highway transportation fleet is large, which can reach the farthest $2000 \mathrm{~km}$. Taking the Beijing-Tianjin-Hebei region as an example, more than $90 \%$ of iron ore relies on highway transportation, less than $10 \%$ is railway transportation; more than $80 \%$ of iron ore used by iron and steel enterprises in North China is transported by highway.

Although the development mode that takes highway freight transport as the dominance can get a better guarantee in accessibility and timeliness, is on the basis of the long-term high-intensity labor of lorry drivers, and also pays high environmental and safety costs. According to relevant research, the unit energy consumption of highway and railway transportation is in a declining state, and the energy consumption of railway and waterway transportation freight is much lower than highway because of the development of power technology. In 2017, the unit energy consumption of railway freight is 4.3 grams of standard coal/conversion ton and $\mathrm{km}$, and the waterway is 2.38 grams of standard coal/conversion ton and $\mathrm{km}$, which account for the equivalent of $24 \%$ and $13.2 \%$ of highway professional freight (18 grams of standard coal/conversion ton and $\mathrm{km}$ ). Compared with highway transportation, railway and waterway freight transportations also have obvious advantages in 
reducing social logistics cost, improving comprehensive transportation efficiency and increasing transportation reliability.

The main reasons for the unreasonable transportation structure in China are: Firstly, the shortage of railway freight transportation capacity in China. With the rapid construction of China's high-speed railway and speed railway network, although railway freight transport capacity has been released, some freight lines, busy trunk lines and zone capacity have reached a saturation, and the progress of railway facilities construction of some enterprises such as steel, electricity, automobile manufacturing in some industrial provinces is sluggish. Secondly, the connection of cross-mode facilities and equipment is not smooth. The railway connection level in port, park, mining area, and manufacturing enterprises is low, only 39 of 70 important ports in China have introduced into the railway dedicated line, and only $25 \%$ possess the railway transport ability in 1210 logistics Park around the country, therefore, highway transport is the only choice in most cases. Thirdly, the road transportation market is not standard. The "small, scattered, messy" phenomenon in the main body of road freight market is widespread, the market body is too scattered, the operation mode is extensive, and the market order is relatively chaotic. Fourthly, the freight rates relationship is not reasonable. Compared with highway transportation, the mechanism of railway transportation market is not flexible, the timeliness, convenience and reliability are insufficient, the price advantage is not obvious, and there is a "price inversion" phenomenon in highway and railway.

\section{Enlightenment and Expectation}

\subsection{Improving the Transportation Structure Adjustment to Local Conditions}

According to the actual conditions of different regions and ports to take the measures of transportation structure adjustment, and for the ports in Beijing-Tianjin-Hebei region with insufficient railway transportation, its drawbacks need to be corrected to break the bottleneck of "highway is the only choice for evacuation of cargoes"; In the Yangtze River Delta region, we should give full play to the advantages of inland river network, focus on promoting the way of intermodal transportation such as river and ocean combined transportation and river-sea transportation.

\subsection{Quickening the Railway Construction Progress, and Striving to Develop Multimodal Transport}

We should promote the construction of collecting and distributing transportation channels such as highways and railways to ensure the direct connection between container port area and expressway and railway; carry forward the upgrading of river and ocean combined transportation/river-sea transportation to provide more efficient, environmentally friendly and low-cost solutions for collecting distributing ports.

\subsection{Propelling Industries to Distribute to Port-Surrounding and Railway-Surrounding Areas to Give Full Play to the Supporting Role of Transport for Economy}

Encouraging the industries with large demand for railway and port transportation to distribute to port-surrounding and railway-surrounding areas to reduce logistics costs and give full play to the supporting and driving role of transportation hubs and transport corridors for industrial development; accelerating the upgrading of the modern service industry, and promoting the optimization and upgrading of the industrial structure in port-surrounding area to carry forward the continuous expansion of port function, enhance its specialization and public service capacity, and meet the needs of high quality development of urban economy.

\section{References}

[1]. CHEN Shu-Iing, KANG Zhao-xia, WU Jian-hong. Inspirations from an International Comparative Study of Structural Adjustment Policies. Railway Transport and Economy, 2018(2): 33-37. 
[2]. Cause analysis of comprehensive transport structure in China. Comprehensive Transportation, 2003(9): 8-11.

[3]. YANG Hua-long, JIAN Ling-xiang, SUN Guang-qi. Analysis on Adiustment of TransPortation Strueture in China. Journal of Transportation Systems Engineering and Information Technology, 2002(5): 11-18.

[4]. ZUO Da-jie, ZENG Jiang, TANG Jian-qiao. Influence factors and optimization enlightenment of comprehensive transport structure evolution. Comprehensive Transportation, 2014(6): 8-11. 